\title{
Ontogeny of phototactic behavior in red drum larvae (Sciaenidae: Sciaenops ocellatus)
}

\author{
D. E. Stearns ${ }^{1,2}$, G. Joan Holt ${ }^{3}$, R. B. Forward Jr ${ }^{4}$, P. L. Pickering ${ }^{3}$ \\ ${ }^{1}$ Department of Biology, Rutgers University, Camden, New Jersey 08102, USA \\ ${ }^{2}$ Institute of Marine and Coastal Sciences, Rutgers University, New Brunswick, New Jersey 08901, USA \\ ${ }^{3}$ University of Texas at Austin, Marine Science Institute, Port Aransas, Texas 78373-1267, USA \\ ${ }^{4}$ Duke University Marine Laboratory, Pivers Island, Beaufort, North Carolina 28516-9721, USA
}

\begin{abstract}
Phototactic behavior of red drum Sciaenops ocellatus larvae (age $=1$ to $17 \mathrm{~d}$ posthatch, size $=2.5$ to $7.5 \mathrm{~mm}$ standard length) was examined. Numerical percent of test larvae phototactically responding per sample was determined after dark and light adaptation upon exposure to different stimulus light intensities and compared with dark or light controls. The relative spectral composition in these experiments was similar to that measured at mid-afternoon at $1 \mathrm{~m}$ depth in a coastal channel where red drum larvae naturally occur. Day 1 larvae were not photoresponsive; all tested older larvae showed positive phototaxis at higher stimulus intensities [ $\geq \mathrm{ca} 10^{-4}$ (Day 16) to $10^{-1}$ (Day 3) $\mu \mathrm{E} \mathrm{m}^{-2} \mathrm{~s}^{-1}$ ] and negative phototaxis at lower light levels [as low as ca $10^{-5}$ (Day 3) to $10^{-7}$ (Day 5) $\mu \mathrm{E} \mathrm{m}^{-2} \mathrm{~s}^{-1}$ ]. The light range for positive phototaxis generally increased with larval age, as did the percent positive response when tested at the same light levels. These results indicate an ontogenetic increase in photoresponsiveness, beginning as early as Day 3 posthatch. Light-adapted larvae as young as Day 4 exhibited a lower response than dark-adapted larvae at the same stimulus intensities, indicating dark and light adaptation. Estimated intensity thresholds for negative phototaxis were compared with nearbottom daylight intensities in 2 coastal channels where red drum larvae occur. Results indicate there is sufficient daylight available throughout the water column in the field for photoperception by red drum larvae. Using an estimate from the literature of a 3 to $4 \log$ unit higher threshold for feeding than for negative phototaxis, we conclude that natural intensities at depth are adequate for visual predation during daylight hours
\end{abstract}

KEY WORDS: Fish larvae - Light responses - Ontogeny · Photosensitivity - Phototaxis · Vision Visual predation · Red drum · Sciaenops ocellatus

\section{INTRODUCTION}

Visual performance of larval fish generally improves with age (Volkova 1973, Durbin 1979, Hairston et al. 1982, Neave 1984, Li et al. 1985, Wanzenböck \& Schiemer 1989, Zaunreiter et al. 1991), and there is strong evidence that prey perception distance increases with body length of the larval predators (see review by Blaxter 1986).The light range for potential visual predation is determined by the predator's photosensitivity threshold, the lowest light intensity that it can perceive. There is little information regarding the ontogeny of photosensitivity for a given fish species (see reviews by Blaxter 1986 and Kotrschal et al. 1990, Champalbert et al. 1991), particularly information regarding short-interval ( 1 to 2 d) changes in larval photosensitivity (e.g. Branchek 1984). This is surprising given the importance of vision in predator-prey relationships that to a large degree determine the survival of what is generally considered the most vulnerable stage of fish development: the larva.

Within a few days after hatching, red drum larvae (Sciaenidae: Sciaenops ocellatus) have used up their yolk-sac food reserves and must assume a carnivorous habit to obtain food for survival and growth (Roberts et al. 1978). Holt et al. (1981) observed active predation by red drum larvae when the yolk sac was exhausted and the mouth and eyes were developed ( $3 \mathrm{~d}$ old $)$; Lee et al. (1984) also reported the onset of active feeding at Day 3 to 4 when post-yolk-sac larvae were about 
$2.7 \mathrm{~mm}$ long. Peters \& McMichael (1987) collected 800 red drum larvae in Tampa Bay, Florida, USA, from 1981 to 1983 . Their collections were completed at night, and they found that fully $85 \%$ of larval stomachs were nocturnally empty. These studies suggest that red drum larvae are diumal, visual feeders.

Phototaxis is defined as directional movement in relation to a directional light source. A positive response is toward the light source, while movement away is negative. While an organism may still perceive light at an intensity that does not elicit phototaxis, phototactic assays provide a conservative range of clearly perceived light intensities. With this in mind, we investigated the ontogeny of phototactic behavior in red drum larvae ranging in age from 1 to $17 \mathrm{~d}$ posthatch, in size from 2.5 to $7.5 \mathrm{~mm}$ standard length (SL, the distance from the tip of the upper jaw to the end of the notochord).

\section{MATERIALS AND METHODS}

Red drum larvae from spawn shed by adults in captivity were raised at $27^{\circ} \mathrm{C}$ and 25 to $31 \%$ using standard culturing techniques (Holt et al. 1990) and facilities at the University of Texas Marine Science Institute, Port Aransas, Texas, USA. Lighting was timed to coincide with the natural photoperiod. Prior to an experiment, test organisms were separated from their food and sorted into $10 \mathrm{ml}$ beakers containing $2.0 \mu \mathrm{m}$ filtered seawater. There were at least 9 test larvae per sample; $85 \%$ of the samples contained 10 to 15 larvae. For dark-adaptation experiments, the larvae were allowed to dark-adapt for at least $1 \mathrm{~h}$ prior to testing for photoresponsiveness (Nicol 1963). To restrict the effects of a possible day/night rhythm in phototaxis (Kawamoto \& Konishi 1955) or swimmimg activity (Massicotte \& Dodson 1991), all experiments were performed in a light-tight room during only the light phase of the photoperiod.

The white light stimulus source was a Kodak AF-2 Ektagraphic slide projector fitted with an ELH, $300 \mathrm{~W}$, $120 \mathrm{~V}$ tungsten lamp (General Electric) or a Kodak Carousel 4400 slide projector fitted with an FHS, $300 \mathrm{~W}, 82 \mathrm{~V}$ tungsten lamp (General Electric). Heat absorbing filters and projector fans were used to reduce heat. Neutral density filters were used to control light intensity. The light source was surrounded by a light shield to prevent leakage of stray light.

The relative visible light emission spectrum of each of the tungsten lamps was measured directly using a scanning spectroradiometer positioned the same distance from the light source as the phototaxis test chamber, in air. At 10 nm wavelength intervals (range $=410$ to $700 \mathrm{~nm}$, considered $100 \%$ of light emitted), the quantal light intensity was measured 125 times, then averaged and summed across the range. The percentage of total intensity across that visible range being emitted at each $10 \mathrm{~nm}$ interval was then calculated. The resulting relative visible light emission spectra for these 2 lamps were found to be similar to the mid-afternoon relative transmission spectrum of light at $1.0 \mathrm{~m}$ depth in a typical coastal plain estuary where red drum larvae naturally occur (Fig. 1), measured using an underwater scanning spectroradiometer (Model 3100 , Gamma Scientific, Inc.) with a cosine collector over the sensor.

A horizontal, plexiglass trough $(19 \mathrm{~cm}$ long $\times 2.5 \mathrm{~cm}$ wide $\times 3.0 \mathrm{~cm}$ high) was used for the phototaxis experiments. The trough had 5 chambers of equal size separated by liftable partitions. It was positioned so that the beam of light from the projector passed horizontally along its long axis (Fig. 2). Light intensities (400 to $700 \mathrm{~nm}$ ) were measured using a LI-COR LI-210S quantum sensor connected to a LI-COR LI-185A quantum meter

The general procedure was the same for each experiment. Neutral density filters were used to select the
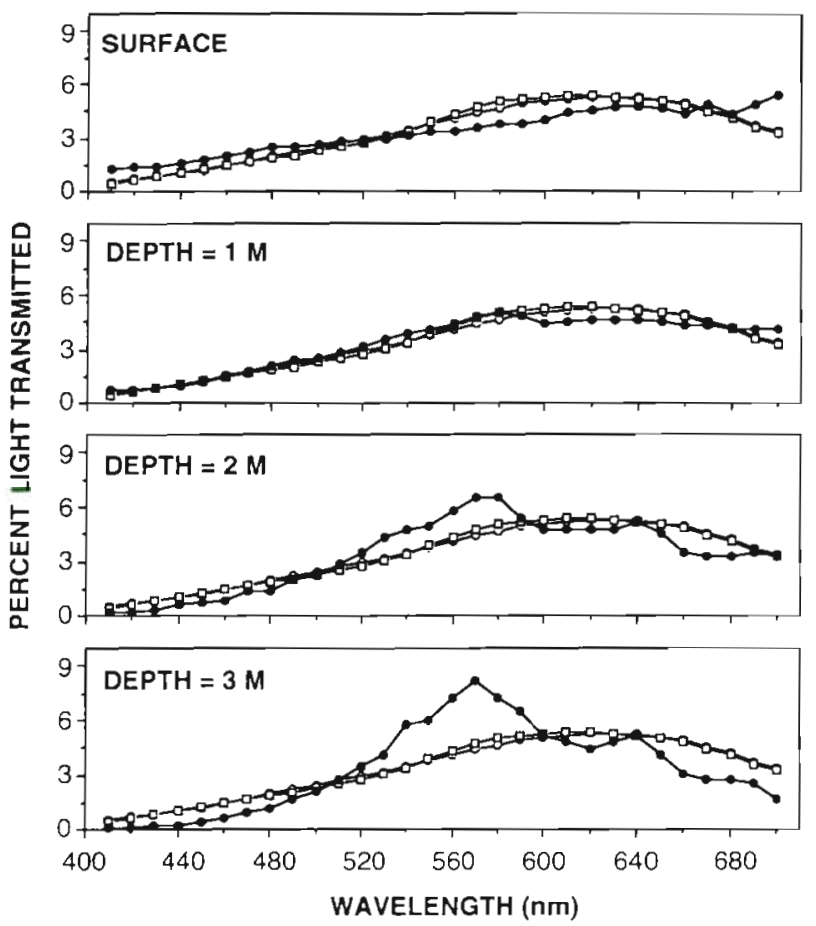

Fig. 1. Comparison of the relative quantal spectral transmission of light from the experimental tungsten lamps [ELH, $300 \mathrm{~W}, 120 \mathrm{~V}$ lamp (0); FHS, $300 \mathrm{~W}, 82 \mathrm{~V}$ lamp (0)] and relative spectral transmission of mid-afternoon sunlight to a depth of $3 \mathrm{~m}$ in the Beaufort Channel near the mouth of the Newport River estuary, Beaufort, North Carolina, USA (•). ('- appears when $\bullet$ and a are superimposed.) Intensity integrated over the 30 data points for each curve is considered $100 \%$ 
appropriate light intensity. The initial restriction of the test larvae to the middle chamber prior to light stimulation could not be done, because the younger stages would stick to the inserted partitions. The trough was therefore positioned without partitions and filled with $2.0 \mu \mathrm{m}$ filtered seawater. All lights were turned off except an overhead dark room lamp fitted with a Kodak safelight filter (Cat. No. 1521483). This safelight was tested and found not to affect the distribution of the fish larvae in the horizontal trough when compared with dark controls in preliminary experiments. This overhead dark room lamp was turned on for only a few seconds while a group of darkadapted fish larvae was gently poured into the middle of the trough. The larvae were then left in darkness for $1 \mathrm{~min}$ before the light stimulus was turned on. Preliminary tests showed that a $4 \mathrm{~min}$ stimulation period allowed sufficient time for the experimental larvae to respond phototactically. After such stimulation the partitions were inserted into the horizontal trough and a flashlight was used to count the larvae in each chamber of the trough. Larvae in the chamber closest to the light source were considered positively phototactic; those in the chamber furthest from it were considered negatively phototactic. The percentage of individuals in each chamber was calculated for each experimental test. Between tests the trough was rinsed with filtered seawater to remove all tested larvae. No fish larva was tested more than once each day.

Because the experimental organisms could not be initially confined to the middle chamber prior to stimulation, 2 specific methods were adopted, one for measuring positive phototaxis at high intensities, another for measuring negative phototaxis at low intensities. For positive phototaxis experiments, larvae were gently poured from a beaker tipped away from the direction of the light source, to minimize the number of larvae being added in this manner to the chamber closest to the light source, so that a false positive response was less likely. For negative phototaxis experiments, larvae were poured from a beaker tipped towards the direction of the light source. Positive phototaxis at high light intensities and negative phototaxis at low light levels were thus determined using different data sets involving these 2 variations of the general procedure.

Dark controls were completed using the method described for positive phototaxis but without light stimulation. The percentage found in the chamber closest to the projector was our measure of relative abundance in the absence of light stimulation. Due to the symmetry of the horizontal trough and the absence of directional cues, this percentage was used as the dark control for both positive and negative phototaxis experiments. Preliminary testing showed no difference when comparing the percentage found in the chamber closest to the projector using the positive phototaxis method with that found in the chamber furthest from the projector using the negative phototaxis method.

Using this general procedure, we tested the phototactic responses of dark-adapted red drum larvae ranging in age from 1 to $17 \mathrm{~d}$ posthatch upon exposure to several light intensities. For each of 147 larval stage/light intensity treatments, replicate size ranged from 3 to 17 (mean $=7.22$ replicates $\pm 0.203 \mathrm{SE}$ ), Replicate size was $\geq 5$ in $95.2 \%$ of the treatments, and $\geq 7$ in $73.4 \%$ of the treatments.

Each dark-adapted treatment was compared with the corresponding dark control after arcsine transformation of all percentage data. For each control/ treatment combination showing homoscedasticity (Bartlett's test; Sokal \& Rohlf 1981), comparison testing was done with a 1-way, Model I analysis of variance (1-way ANOVA). For each combination showing heteroscedasticity, the nonparametric Kruskal-Wallis test was used.

Experiments involving light-adapted fish larvae (Days $4,6,10 \& 16$ ) were also completed, to see if such adaptation occurs early in the development of this species, determined by comparing dark- and lightadapted responses to the same light stimuli. These larvae were tested for positive phototactic responses after being light-adapted for at least $1 \mathrm{~h}$ to a white light intensity of $12 \mu \mathrm{E} \mathrm{m}^{-2} \mathrm{~s}^{-1}$ from an overhead white fluorescent lamp (Philips Lighting Model F40D). Light controls were treated identically to dark controls except for light adaptation prior to testing. In a manner similar to that described for the dark-adapted treatments, each light-adapted treatment was compared with the corresponding light control after arcsine transformation of all percentage data.

Correlation coefficients were calculated to estimate the degree of association between the stimulus light intensity $\left(\mu \mathrm{E} \mathrm{m}^{-2} \mathrm{~s}^{-1}\right)$ after $\log (X+1)$ transformation 
$\left(=Y_{1}\right)$ and the percent positive phototactic response after arcsine transformation $\left(=Y_{2}\right)$ for each photoresponsive red drum larval age group tested after darkadaptation. With discontinuous $Y_{1}$ groupings and $>1$ $Y_{2}$ value for each $Y_{1}$, each correlation was calculated using mean $Y_{2}$ values. Parametric product-moment correlation coefficients (I) were calculated when the data set for the age group showed normality for each $Y_{1}$ group (Kolmogorov-Smirnov test for goodness of fit; Sokal \& Rohlf 1981) and when the $Y_{1}$ groups showed homoscedasticity (Bartlett's test; Sokal \& Rohlf 1981). Otherwise, nonparametric Kendall coefficients of rank correlation $(\tau)$ were determined. Similarly, $r$ and $\tau$ values were calculated to discern, for each stimulus intensity, the association between larval age (our first estimator of development, $Y_{1}$ ) and percent positive phototactic response after arcsine transformation $\left(\mathrm{Y}_{2}\right)$. Light-adapted treatments were not analyzed in this manner, because there were not enough $Y_{1}$ groups $(<5)$ in each data set to allow $\tau$ determinations (Sokal \& Rohlf 1981).

At each light intensity for which both dark-adapted and light-adapted fish larvae were tested for positive phototaxis, dark- and light-adapted groups were statistically compared after arcsine transformation of the percentage data. Most comparisons were done using 1 -way ANOVAs. Two comparisons (Day 4 larvae, light intensity $=3.35 \mu \mathrm{E} \mathrm{m}^{-2} \mathrm{~s}^{-1}$; Day 6 larvae, light intensity

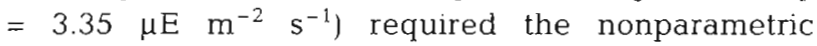
Kruskal-Wallis test due to heteroscedasticity (Sokal \& Rohlf 1981).

Standard lengths of anesthetized (MS 222) larvae were measured as an additional descriptor of development. Jandel Scientific SIGMASCAN 3.90 software, with a Summasketch digitizing tablet and mousepuck, and a Wild M8 stereomicroscope equipped with a drawing tube, were used to measure the standard length of each larva. Following the same statistical correlational procedure described earlier, $r$ and $\tau$ values were calculated to estimate, for each stimulus intensity, the degree of association between standard length after $\log$ transformation (our second estimator of development, $Y_{1}$ ) and percent positive phototaxis after arcsine transformation $\left(Y_{2}\right)$. Too few $Y_{1}$ groups per data set $(<5)$ prevented $\tau$ determinations for light-adapted treatments.

The threshold light intensities for eliciting phototaxis in red drum larvae were compared with daytime light levels measured close to the bottoms of 2 coastal channels that serve as natural habitats of Sciaenops ocellatus larvae: the Beaufort Channel near the mouth of the Newport River estuary, Beaufort, North Carolina, USA, and the Lydia Ann Channel near Port Aransas, Texas, USA. Downwelling light (400 to $700 \mathrm{~nm}$ ) was measured in the Lydia Ann Channel using a LI-COR LI-192S underwater quantum sensor with an upward-facing cosine collector connected to a LI-1000 quantum meter. For 9 d (2 in June-July, 2 in October, 5 in December), hourly or bihourly near-bottom daytime light measurements were made in the Beaufort Channel. For the June-July and December field studies, $4 \pi$ quantal readings ( 400 to $700 \mathrm{~nm}$ ) were made using a LI-COR 193S spherical quantum sensor and LI-COR printing integrator (Model 550) fitted with either the $190 \mathrm{M}$ or the more sensitive $192 \mathrm{M}$ module. For the October field study, downwelling light measurements were made using a submarine radiometer (Kahl Corporation, Model 268WA310) with an upward-facing cosine collector. These October measurements were then corrected to $4 \pi$ quantal intensities ( 400 to $700 \mathrm{~nm}$ ) (p. 526 of Stearns 1983).

\section{RESULTS}

Fig. 3 summarizes the results of the photopositive experiments. Dark-adapted, Day 1 larvae were nonresponsive, with no significant change in positive phototaxis from the dark control group, regardless of the tested light intensity (Kruskal-Wallis 1-way analysis by ranks, $H_{\text {adj }}=1.426, \mathrm{p}=0.921$ ). For each developmental stage except Day 1 , however, there was a general increase in the positive phototaxis of larvae with increase in light intensity, regardless of dark or light adaptation. Table 1 shows, for each dark-adapted, photoresponsive larval age tested, a significant, positive correlation between light intensity and response.

Table 2 and Fig. 3 allow a comparison of photopositive responses for dark-and light-adapted fish larvae when tested at the same light intensities. Within each tested age group, light-adapted larvae generally showed a lower response than dark-adapted larvae except at the highest light levels. The differences were often statistically significant (Table 2). Light-adapted larvae often required a light stimulus 1 to 1.2 orders of magnitude higher in intensity to elicit the same level of photopositive response found for dark-adapted larvae.

Table 3 and Fig. 3 allow ontogenetic comparisons of positive phototactic responses to the same light intensities. For each tested light level, Table 3 shows the degree of association between larval age and darkadapted, positive phototaxis; it also shows the degree of association between standard length and positive phototaxis. Beyond the nonresponsive Day 1 stage, the red drum larvae showed a highly positive, usually significant $(p<0.05)$ correlation between larval age and positive response, as well as between standard length and positive response. Analysis of data pooled across all experimental treatments showed a highly significant positive correlation between age (range = 
Fig. 3. Sciaenops ocellatus. Ontogenetic changes in light intensity versus phototactic response curves for larvae (mean $\pm \mathrm{SE}$, mean $\mathrm{n}=7.22$ replicates per treatment $\pm 0.203 \mathrm{SE}$ ). Standard error and number of replicates for each control are shown in parentheses. $\star$ : mean negative response that is significantly ( $\mathrm{p}<0.05$ ) different from the dark control. > : lowest light intensity where darkadapted (above ' $\bullet$ ') or lightadapted (below ' $x$ ') positive response is significantly ( $\mathrm{p}<$ 0.05 ) higher than the appropriate control; all higher intensities elicited significant responses. The abscissa is a log scale
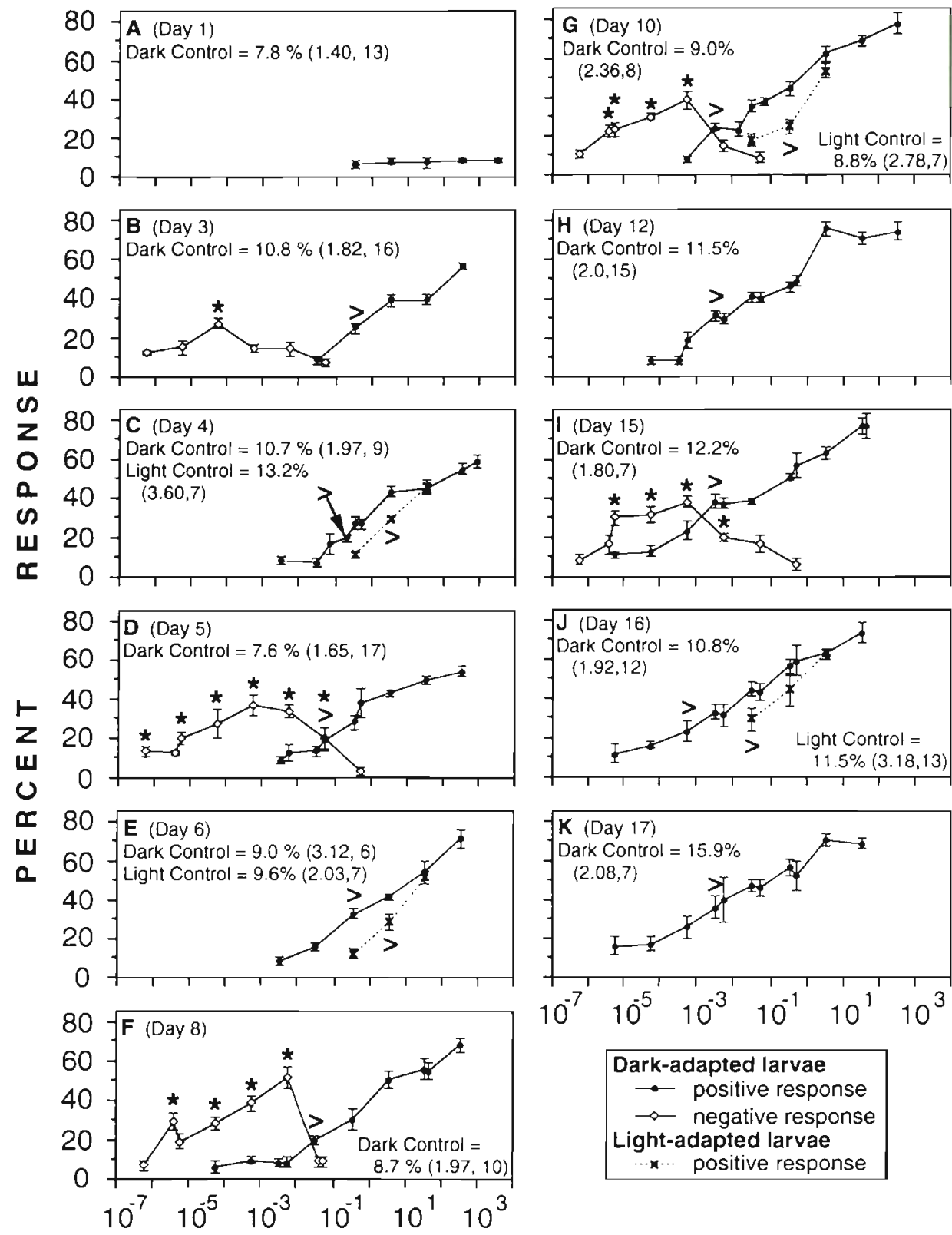

\section{LIGHT INTENSITY $\left(\mu \mathrm{E} \mathrm{m}^{-2} \mathrm{~s}^{-1}\right)$}

1 to $17 \mathrm{~d}$ posthatch) and standard length (range $=2.5$ to $7.5 \mathrm{~mm} \mathrm{SL})(\mathrm{r}=0.843, \mathrm{n}=1146$ observations, $\mathrm{p}<$ $0.00001)$

Fig. 3 also summarizes the results of the photonegative experiments. For each larval age tested (Days 3, 5, 8,10 and 15), negative phototaxis occurred at light levels much lower than those for positive phototaxis and is indicative of phototactic sign switching. Although the negative and positive phototactic experiments were done independently, the 2 responses showed opposite trends at the overlapping light intensities: as one response increased in magnitude, the other decreased.
These results can be summarized as follows for each group tested: at low light levels the larvae showed a negative response, moving away from the light source. As the stimulus intensity increased, so did this negative response. At still higher light levels, the negative response decreased while the positive response began to increase, evidence of phototactic sign switching. The intensity range over which sign switching occurred changed with larval age (Fig. 3).

We determined for each dark-adapted larval stage the lowest light intensities that elicited significant $(\mathrm{p}<$ $0.05)$ negative and positive phototaxis when compared 
Table 1. Parametric product-moment correlation coefficients (r) and nonparametric Kendall coefficients of rank correlation

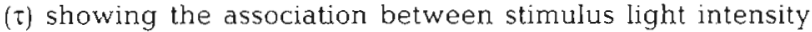
$\left(\mu \mathrm{E} \mathrm{m} \mathrm{m}^{-2} \mathrm{~s}^{-1}\right)$ after $\log (X+1)$ transformation and percent positive phototactic response after arcsine transformation, for dark-adapted Sciaenops ocellatus larvae at different larval ages (days posthatch). Nonresponsive Day 1 larvae were excluded. Each light-adapted treatment was excluded because $\mathrm{n}<5$, the minimum $\mathrm{n}$ required for $\tau$ calculations. $\mathrm{n}$ : number of light intensity groups, the means of which were used for each correlation calculation; p: significance level

\begin{tabular}{|ccccr|}
\hline Larval age (d) & $\mathrm{r}$ & $\tau$ & $\mathrm{p}$ & $\mathrm{n}$ \\
\hline 3 & & 0.867 & 0.0146 & 6 \\
4 & 0.953 & & 0.00001 & 11 \\
5 & & 1.000 & 0.0001 & 10 \\
6 & & 0.905 & 0.0043 & 7 \\
8 & 0.884 & & 0.0003 & 11 \\
10 & & 0.911 & 0.0002 & 10 \\
12 & & 0.821 & 0.0001 & 13 \\
15 & 0.679 & 0.909 & $<0.0001$ & 12 \\
16 & 0.657 & & 0.01508 & 12 \\
17 & & & 0.02029 & 12 \\
\hline
\end{tabular}

with unstimulated controls (Table 4). In general, the older the larval stage, the lower the threshold light intensity for positive phototaxis $(\tau=-0.774, p=0.0014$, $\mathrm{n}=10$ observations). No such association between age and threshold light intensity was found for negative phototaxis ( $\tau=0.105, \mathrm{p}=0.7984, \mathrm{n}=5$ observations). With respect to negative phototaxis, we estimated a threshold intensity of approximately $5.6 \times 10^{-5} \mu \mathrm{E} \mathrm{m} \mathrm{m}^{-2}$ $\mathrm{s}^{-1}$ for Day 3 larvae, changing to $5.6 \times 10^{-7} \mu \mathrm{E} \mathrm{m}^{-2} \mathrm{~s}^{-1}$ by Day 5 . Older larval stages did not exhibit negative phototaxis at lower light intensities (range $=5.6 \times 10^{-6}$ to $3.96 \times 10^{-6} \mu \mathrm{E} \mathrm{m}^{-2} \mathrm{~s}^{-1}$ ).

The Beaufort Channel near-bottom light data are presented in Fig. 4. In this relatively shallow system (depth range for these light readings $=1.25$ to $3.0 \mathrm{~m}$ ), the lowest daytime intensity measured was $2.0 \mu \mathrm{E} \mathrm{m}-2$ $\mathrm{s}^{-1}$, shortly after sunrise and shortly before sunset, October 8 (Fig. 4A). Near-bottom intensities were usually 1 to 2 orders of magnitude higher during the day, regardless of season. By contrast, the Lydia Ann Channel location was deeper (total depth $=8.2 \mathrm{~m}$ ). The lowest intensity measured just above the bottom (depth $=$ $8 \mathrm{~m}$ ) of this channel in June was $2.0 \times 10^{-1} \mu \mathrm{E} \mathrm{m}^{-2} \mathrm{~s}^{-1}$. Despite these differences, even the lowest daytime bottom light intensities measured at both locations were several orders of magnitude higher than necessary to elicit phototaxis in even the least-sensitive Day 3 red drum larval stage (Table 4 ).

\section{DISCUSSION}

Red drum larvae clearly show changes in phototactic behavior as they age and grow. While Day 1 larvae were not photoresponsive, all tested older larvae showed positive phototaxis at higher stimulus intensities $\left[\geq\right.$ approximately $10^{-4}$ (Day 16 ) to $10^{-1}$ (Day 3) $\mu \mathrm{E}$

Table 2. Sciaenops ocellatus. Comparisons of positive phototactic responses of dark-adapted (D) and light-adapted (L) larvae tested at the same stimulus light intensities. All testing was done using arcsine-transformed data. The sample size of each group is presented in parentheses. SE: standard error of the mean; $F_{\mathrm{s}}$ : $F$-statistic resulting from 1 -way ANOVA; $H_{\text {adj: }}$ adjusted $H$ statistic resulting from Kruskal-Wallis test

Stimulus intensity

$\left(\mu \mathrm{E} \mathrm{m}^{-2} \mathrm{~s}^{-1}\right)$

\section{Percent positive phototaxis} $($ mean \pm SE)

$\mathrm{D}$

$$
\begin{aligned}
& 27.3 \pm 3.53(8) \\
& 43.4 \pm 2.55(7) \\
& 44.7 \pm 2.86(7)
\end{aligned}
$$

$32.9 \pm 2.86(7)$

$41.5 \pm 1.74(8)$

$54.8 \pm 4.52(9)$

$35.8 \pm 2.79(11)$

$44.8 \pm 3.94(7)$

$62.5 \pm 3.53(7)$

$44.4 \pm 3.95(7)$

$56.2 \pm 3.64(7)$

$62.6 \pm 1.91(7)$
$11.1 \pm 1.19(7)$

$29.5 \pm 0.93(7)$

$46.1 \pm 3.57(7)$

$11.9 \pm 2.55(8)$

$28.6 \pm 4.42(7)$

$51.5 \pm 2.93(8)$

$18.3 \pm 3.17(7)$

$24.8 \pm 3.53(7)$

$53.8 \pm 3.68(7)$

$29.1 \pm 5.85(3)$

$43.6 \pm 7.39(5)$

$62.8 \pm 2.50(7)$
Result

Statistic

$$
\begin{aligned}
& 3.35 \times 10^{-2} \\
& 3.35 \times 10^{-1} \\
& 3.35
\end{aligned}
$$

$$
\begin{aligned}
& D>L \\
& D>L \\
& D=L
\end{aligned}
$$$$
\mathrm{D}>\mathrm{L}
$$$$
\mathrm{D}>\mathrm{L}
$$$$
\mathrm{D}=\mathrm{L}
$$$$
D>L
$$$$
\mathrm{D}>\mathrm{L}
$$$$
\mathrm{D}=\mathrm{L}
$$

$\mathrm{D}=\mathrm{L}$

$\mathrm{D}=\mathrm{L}$

$\mathrm{D}=\mathrm{L}$

$$
\begin{array}{rlrl}
F_{\mathrm{s}} & =21.92 & & (\mathrm{p}=0.0004) \\
H_{\text {ad }} & =9.45 & & (\mathrm{p}=0.002) \\
F_{\mathrm{s}} & =0.091 & & (\mathrm{p}=0.771) \\
F_{\mathrm{s}} & =19.15 & & (\mathrm{p}=0.0008) \\
H_{\text {ad }} & =5.14 & (\mathrm{p}=0.023) \\
F_{\mathrm{s}} & =0.42 & (\mathrm{p}=0.5338)
\end{array}
$$

$$
F_{S}=18.05 \quad(p=0.0006)
$$$$
F_{5}=17.20 \quad(p=0.0014)
$$$$
F_{\mathrm{s}}=2.79 \quad(\mathrm{p}=0.1206)
$$

$$
\begin{array}{ll}
F_{\mathrm{s}}=4.81 & (\mathrm{p}=0.0597) \\
F_{\mathrm{s}}=2.85 & (\mathrm{p}=0.1222) \\
F_{\mathrm{s}}=0.003 & (\mathrm{p}=0.9583)
\end{array}
$$


Table 3. Sciaenops ocellatus. Parametric product-moment correlation coefficients ( $\mathrm{r}$ ) and nonparametric Kendall coefficients of rank correlation $(\tau)$ showing the association between age (days posthatch) and percent positive phototactic response (arcsine transformed), as well as body size (log standard length in mm) and percent positive response (arcsine transformed), for dark-adapted larvae tested at different stimulus light intensities. Nonresponsive Day 1 larvae were excluded. Each light-adapted treatment was excluded because $n<5$. n: number of age or size groups, the means of which were used for each correlation calculation. Treatments with $\mathrm{n}<5$, the minimum $\mathrm{n}$ required for $\tau$ calculations, were excluded. p: significance level

\begin{tabular}{|c|c|c|c|c|c|c|c|c|}
\hline \multirow{2}{*}{$\begin{array}{l}\text { Light intensity } \\
\left(\mu \mathrm{E} \mathrm{m}^{-2} \mathrm{~s}^{-1}\right)\end{array}$} & \multicolumn{4}{|c|}{ Larval age } & \multicolumn{4}{|c|}{ Standard length } \\
\hline & $r$ & $\tau$ & $\mathrm{n}$ & $p$ & $r$ & $\tau$ & $\mathrm{n}$ & $\mathrm{p}$ \\
\hline $5.6 \times 10^{-5}$ & 0.994 & & 5 & 0.0005 & 0.934 & & 5 & 0.0201 \\
\hline $5.6 \times 10^{-4}$ & 0.917 & & 7 & 0.0100 & 0.863 & & 9 & 0.0028 \\
\hline $3.35 \times 10^{-3}$ & 0.939 & & 9 & 0.0002 & 0.843 & & 17 & $<0.0001$ \\
\hline $5.6 \times 10^{-3}$ & 0.752 & & 6 & 0.0848 & & 0.524 & 7 & 0.0985 \\
\hline $3.35 \times 10^{-2}$ & & 0.956 & 10 & 0.0001 & & 0.648 & 14 & 0.0012 \\
\hline $3.35 \times 10^{-1}$ & 0.977 & & 10 & $<0.0001$ & 0.870 & & 15 & $<0.0001$ \\
\hline $5.6 \times 10^{-1}$ & 0.944 & & 6 & 0.0046 & 0.633 & & 6 & 0.1774 \\
\hline 3.35 & 0.864 & & 10 & 0.0013 & 0.894 & & 14 & $<0.0001$ \\
\hline $3.35 \times 10^{1}$ & & 0.778 & 10 & 0.0017 & & 0.661 & 16 & 0.0003 \\
\hline $3.35 \times 10^{2}$ & & 0.524 & 7 & 0.0985 & & 0.619 & 7 & 0.0509 \\
\hline
\end{tabular}

$\mathrm{m}^{-2} \mathrm{~s}^{-1}$ ] and negative phototaxis at lower light levels [as low as approximately $10^{-5}$ (Day 3) to $10^{-7}$ (Day 5) $\mu \mathrm{E} \mathrm{m}^{-2} \mathrm{~s}^{-1}$ ]. The light range over which positive phototaxis occurred generally increased with larval age, as did the percent positive phototactic response when tested at the same light levels. These results indicate an ontogenetic increase in photoresponsiveness, beginning as early as Day 3 posthatch.

Using phototactic behavioral assays, Blaxter (1968a) and Wales (1984) reported that herring Clupea harengus larvae exhibited positive phototaxis at higher white light intensities and negative phototaxis at lower intensities. Blaxter (1969) similarly found negative phototaxis at low light levels in plaice Pleuronectes platessa larvae and sole Solea solea larvae, as well as some evidence of positive phototaxis at higher intensi-

Table 4. Sciaenops ocellatus. Ontogenetic changes in photoresponsiveness of larvae, as estimated by lowest tested light intensities to evoke significant $(p<0.05)$ negative and positive phototaxis in dark-adapted organisms (Day 1 larvae were not responsive). Light intensity units are $\mu \mathrm{E} \mathrm{m}^{-2} \mathrm{~s}^{-1}$

\begin{tabular}{|ccc|}
\hline $\begin{array}{c}\text { Larval } \\
\text { age }\end{array}$ & $\begin{array}{c}\text { Lowest intensity } \\
\text { to evoke negative } \\
\text { phototaxis }\end{array}$ & $\begin{array}{c}\text { Lowest intensity } \\
\text { to evoke positive } \\
\text { phototaxis }\end{array}$ \\
\hline Day 3 & $5.6 \times 10^{-5}$ & $3.35 \times 10^{-1}$ \\
Day 4 & - & $2.0 \times 10^{-3}$ \\
Day 5 & $5.6 \times 10^{-7}$ & $5.6 \times 10^{-2}$ \\
Day 6 & - & $3.35 \times 10^{-1}$ \\
Day 8 & $3.96 \times 10^{-6}$ & $3.35 \times 10^{-2}$ \\
Day 10 & $3.96 \times 10^{-6}$ & $3.35 \times 10^{-3}$ \\
Day 12 & - & $3.35 \times 10^{-3}$ \\
Day 15 & $5.6 \times 10^{-6}$ & $3.35 \times 10^{-3}$ \\
Day 16 & - & $5.6 \times 10^{-4}$ \\
Day 17 & - & $3.35 \times 10^{-3}$ \\
\hline
\end{tabular}

ties. More recently, Champalbert et al. (1991) confirmed such phototactic sign switching in $S$. solea larvae. Our red drum threshold phototaxis intensities cannot be compared with those reported by Blaxter (1968a, b, 1969), Wales (1984) and Champalbert et al. (1991), because (1) it is not possible to convert photometric units (meter-candles and luxes of white light used by Blaxter and Wales) to radiometric units (photons) or convert from watts of white light of unknown emission spectrum (used by Champalbert et al. 1991) to photons, (2) the relative emission spectra of the light sources are not likely to be the same, and (3) the different species do not necessarily exhibit similar action spectra for phototaxis. We can say, however, that all these phototactically tested fish exhibit negative responses at very low light levels and positive responses at higher intensities.

The cause of phototactic sign switching found in fish larvae is unknown. It is possible that an extraretinal photoreceptor system is functioning at low light levels, resulting in a change in phototactic response compared with photobehavior mediated by the eyes. However, Wales $(1975,1984)$, using a method similar to that of Blaxter (1968a), tested for and found no phototactic evidence of such a system in blinded Clupea harengus and Pleuronectes platessa larvae, although he did find evidence of extraretinal photosensitivity when larvae were allowed to migrate vertically in response to overhead light cues. It is possible that negative phototaxis at low intensities is rod-mediated (assuming rod development at this stage) while positive phototaxis at higher intensities is cone-mediated, or that different cone systems are controlling these responses.

Similar phototactic sign switching has been reported for many planktonic crustacean species (Herrnkind 1968, Forward 1974, 1976, 1977, 1986, Forward \& 

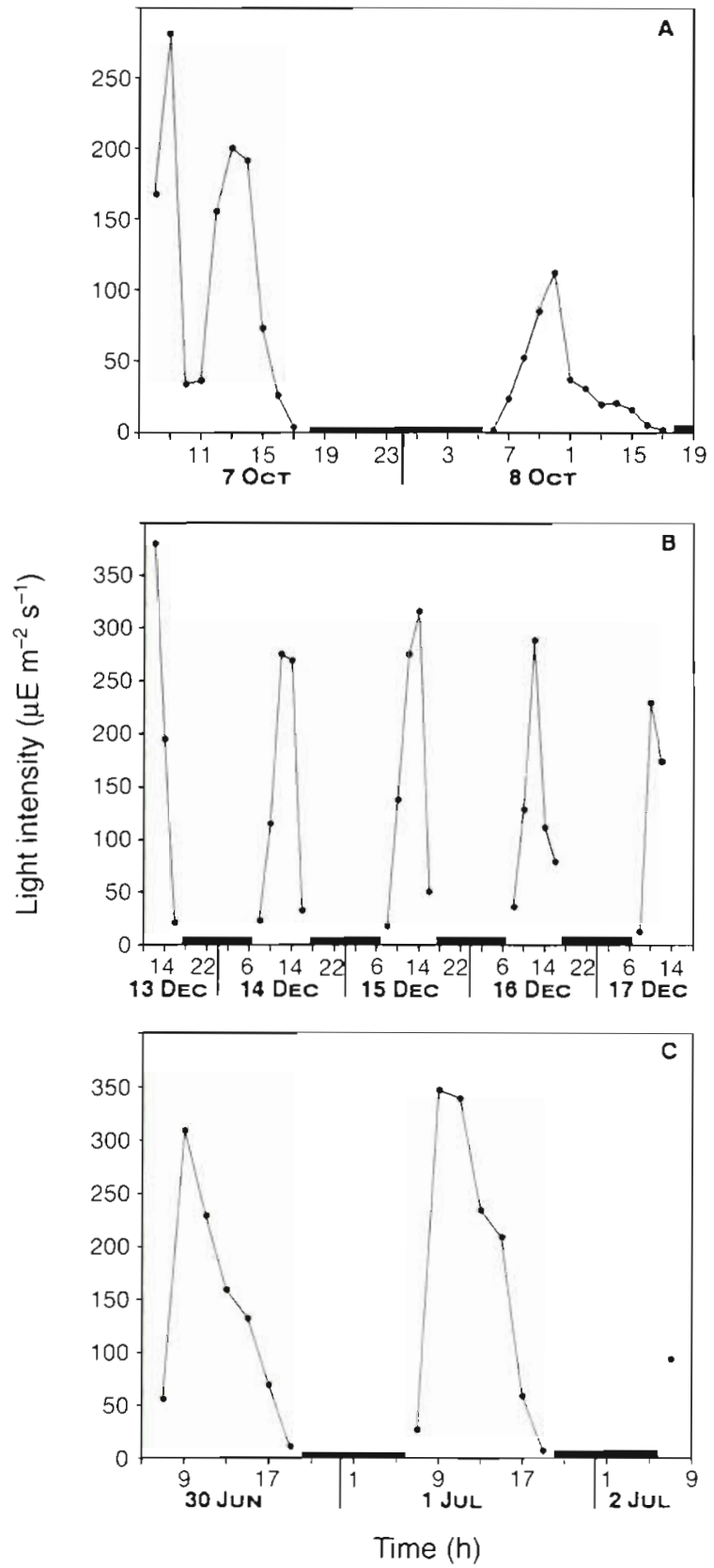

Fig. 4. Daytime near-bottom $4 \pi$ quantal light intensities (400 to $700 \mathrm{~nm}$ ) in Beaufort Channel, Beaufort, North Carolina, USA, during 3 field studies: (A) 7 to 8 October 1977; (B) 13 to 17 December 1978 ; (C) 30 June to 2 July 1979. Dark bars indicate hours of darkness

Costlow 1974, Wilson et al. 1985). While it may be inappropriate to search for adaptive value in an unnatural, highly directional light setup (Verheijen 1958), experiments involving more natural underwater angular light distributions indicate that the negative phototaxis to low light intensities in planktonic crustaceans is part of a predator avoidance shadow response (reviewed by Forward 1988). No research has been done to investigate the possible adaptive role of phototactic sign switching in fish larvae.

Day 4 and Day 6 red drum larvae were phototactically more responsive to stimulus intensities of $3.35 \times 10^{-1}$ and $3.35 \mu \mathrm{E} \mathrm{m} \mathrm{m}^{-2} \mathrm{~s}^{-1}$ when they were dark-adapted than when they were light-adapted (Fig. 3C, E, Table 2). A similar situation was found for Day 10 larvae at $3.35 \times 10^{-2}$ and $3.35 \times 10^{-1} \mu \mathrm{E} \mathrm{m}^{-2} \mathrm{~s}^{-1}$ (Fig. 3G, Table 2). Although not statistically significant, a similar trend was found for Day 16 larvae at $3.35 \times$ $10^{-2}$ and $3.35 \times 10^{-1} \mu \mathrm{E} \mathrm{m}^{-2} \mathrm{~s}^{-1}$ (Fig. 3J, Table 2). The larvae of most euphotic teleosts have a pure-cone retina at first feeding and develop a rod system later (reviewed by Blaxter 1975, 1986, Evans \& Fernald 1990, Kotrschal et al. 1990). The timing of rod development, with concomitant retinomotor movements of the photoreceptors and pigmented epithelium as lightadaptation mechanisms, differs with life history strategy (Blaxter \& Staines 1970, reviewed by Evans \& Fernald 1990). Our results indicate that light-adapted and dark-adapted differences in response occur as early as Day 4 in Sciaenops ocellatus (earlier stages were not tested for this comparison). While rod development may be occurring at this early stage, rods are not necessary to explain such light adaptation. Blaxter (1968a, b, 1969) found light-and dark-adapted differences in photoresponses in rodless herring, plaice and sole larvae, as did Champalbert et al. (1991) for sole larvae, at a stage of development when retinal masking pigments are not photomechanically functional. Blaxter (1968a, b, 1969) suggested that cones differ in their sensitivity to light, so that low-threshold cones may require dark-adaptation before functioning properly.

As primarily visual predators, post-yolk-sac red drum larvae require detectable light for efficient feeding. The amount of light that is sufficient for potential visual predation depends in part on the ability of the predator to see. Our experiments show that Day 1 larvae are not photoresponsive (Fig. 3A). At this stage, they lack pigmented eyes (Holt et al. 1981, pers. obs.). By Day 3, when the eyes and jaws are functional and the larvae can actively search for prey (Holt et al. 1981), they phototactically respond to intensities as low as $5.6 \times 10^{-5} \mu \mathrm{E} \mathrm{m}^{-2} \mathrm{~s}^{-1}$ and by Day 5 to $5.6 \times 10^{-7} \mu \mathrm{E}$ $\mathrm{m}^{-2} \mathrm{~s}^{-1}$ (Table 4). Older larval stages do not appear to exhibit negative phototaxis to lower light intensities (Table 4), but they do increase their percent positive response to a given stimulus intensity as they age and grow (Fig. 3; Table 3).

The lowest light intensity to evoke negative phototaxis in red drum larvae was $5.6 \times 10^{-7} \mu \mathrm{E} \mathrm{m}^{-2} \mathrm{~s}^{-1}$ (Table 4). If we use Blaxter's (1968a, b, 1969) estimate of a 3 to $4 \log$ unit higher threshold for feeding than for 
negative phototaxis, based on similarly collected data for larvae of Clupea harengus, Pleuronectes platessa and Solea solea, the estimated threshold for feeding in red drum larvae is within the approximate range of $5.6 \times 10^{-4}$ to $5.6 \times 10^{-3} \mu \mathrm{E} \mathrm{m}^{-2} \mathrm{~s}^{-1}$.

Because an estuarine water column filled with suspended particles acts as a spectral filter, the relative amount of light of a particular wavelength will vary with depth. The white light used in the phototaxis experiments most closely resembled the relative spectral composition of natural light transmitted to a depth of $1 \mathrm{~m}$ in an estuary near midday (Fig. 1). At greater depths, proportionately less blue and red light are available in the field. If red drum larvae are responding to only the red and/or blue wavelengths, then at depths $>1 \mathrm{~m}$ there may not be enough red and/or blue light for visual predation to occur. In preliminary experiments, however, we found larvae to be very responsive to the mid-spectrum (500 to $600 \mathrm{~nm}$ ), and more so than to the longer wavelengths. The larvae are clearly not responding to only the red and/or blue light.

The lowest measured, daytime, near-bottom field intensity in the Beaufort Channel was $2.0 \mu \mathrm{E} \mathrm{m}^{-2} \mathrm{~s}^{-1}$ ( 400 to $700 \mathrm{~nm}$ ), measured near sunset and sunrise at a depth of $2.8 \mathrm{~m}$ (Fig. $4 \mathrm{~A}$ ). Using the relative transmission spectrum measured in Beaufort Channel for depth $=3 \mathrm{~m}$ (Fig. 1), we estimated the spectral composition of this intensity (Table 5). For each wavelength we then compared the light intensity at $3 \mathrm{~m}$ depth near sunset and sunrise with the upper $\left(5.6 \times 10^{-3} \mu \mathrm{E} \mathrm{m}^{-2} \mathrm{~s}^{-1}\right)$ and lower $\left(5.6 \times 10^{-4} \mu \mathrm{E} \mathrm{m}^{-2} \mathrm{~s}^{-1}\right)$ limits of the estimated white light threshold intensity range for visual feeding in red drum larvae.

For all wavelengths the $3 \mathrm{~m}$ field intensity per wavelength was greater than the lower threshold; for all wavelengths $\geq 450 \mathrm{~nm}$ the field intensity per wavelength was greater than the upper threshold (Table 5). Thus, for most of the visible spectrum at $3 \mathrm{~m}$ depth near sunset and sunrise in the Beaufort Channel, and including the spectral range within which red drum larvae are known to be phototactic, each wavelength alone has enough light available for visual feeding. In each case, we compared a wavelength-specific intensity with 2 threshold white light intensities that are integrated over the entire visible spectrum $(400$ to $700 \mathrm{~nm}$ ), yet we still found above-threshold values for most tested wavelengths. These results indicate that there is plenty of light available for visual predation by red drum larvae at $3 \mathrm{~m}$ depth in the Beaufort Channel from approximately sunrise to sunset.

The mid-afternoon downwelling (not $4 \pi$ ) intensity measured near the bottom of the deeper $(8 \mathrm{~m})$ Lydia Ann Channel was still 35 to 350 times higher than the estimated intensity threshold for visual feeding.
Table 5. Wavelength-specific intensities at $3 \mathrm{~m}$ depth in Beaufort Channel, North Carolina, USA, shortly before sunset and shortly after sunrise during the October field study (Fig. 4) (integrated intensity $=2.0 \mu \mathrm{E} \mathrm{m}^{-2} \mathrm{~s}^{-1}$ ), for comparison with the upper $\left(5.6 \times 10^{-3} \mu \mathrm{E} \mathrm{m}^{-2} \mathrm{~s}^{-1}\right)$ and lower $\left(5.6 \times 10^{-4} \mu \mathrm{E}\right.$ $\left.\mathrm{m}^{-2} \mathrm{~s}^{-1}\right)$ limits of the estimated white (400 to $\left.700 \mathrm{~nm}\right)$ light threshold intensity range for visual feeding in Sciaenops ocellatus larvae

\begin{tabular}{|c|c|c|}
\hline $\begin{array}{l}\text { Wavelength } \\
\qquad(\mathrm{nm})\end{array}$ & $\begin{array}{l}\text { Relative intensity } \\
\qquad(\%)\end{array}$ & $\begin{array}{l}\text { Light intensity } \\
\left(\mu \mathrm{E} \mathrm{m}^{-2} \mathrm{~s}^{-1}\right)\end{array}$ \\
\hline 410 & 0.07 & $1.4 \times 10^{-3}$ \\
\hline 420 & 0.09 & $1.8 \times 10^{-3}$ \\
\hline 430 & 0.17 & $3.4 \times 10^{-3}$ \\
\hline 440 & 0.24 & $4.8 \times 10^{-3}$ \\
\hline 450 & 0.44 & $8.8 \times 10^{-3}$ \\
\hline 460 & 0.58 & $1.2 \times 10^{-2}$ \\
\hline 470 & 0.90 & $1.8 \times 10^{-2}$ \\
\hline 480 & 1.19 & $2.4 \times 10^{-2}$ \\
\hline 490 & 1.69 & $3.4 \times 10^{-2}$ \\
\hline 500 & 2.09 & $4.2 \times 10^{-2}$ \\
\hline 510 & 2.78 & $5.6 \times 10^{-2}$ \\
\hline 520 & 3.48 & $7.0 \times 10^{-2}$ \\
\hline 530 & 4.13 & $8.3 \times 10^{-2}$ \\
\hline 540 & 5.76 & $1.2 \times 10^{-1}$ \\
\hline 550 & 6.0 & $1.2 \times 10^{-1}$ \\
\hline 560 & 7.29 & $1.5 \times 10^{-1}$ \\
\hline 570 & 8.16 & $1.6 \times 10^{-1}$ \\
\hline 580 & 7.29 & $1.5 \times 10^{-1}$ \\
\hline 590 & 6.52 & $1.3 \times 10^{-1}$ \\
\hline 600 & 5.13 & $1.0 \times 10^{-1}$ \\
\hline 610 & 4.8 & $9.6 \times 10^{-2}$ \\
\hline 620 & 4.46 & $8.9 \times 10^{-2}$ \\
\hline 630 & 4.8 & $9.6 \times 10^{-2}$ \\
\hline 640 & 5.13 & $1.0 \times 10^{-1}$ \\
\hline 650 & 4.13 & $8.3 \times 10^{-2}$ \\
\hline 660 & 3.07 & $6.1 \times 10^{-2}$ \\
\hline 670 & 2.69 & $5.4 \times 10^{-2}$ \\
\hline 680 & 2.69 & $5.4 \times 10^{-2}$ \\
\hline 690 & 2.54 & $5.1 \times 10^{-2}$ \\
\hline 700 & 1.73 & $3.5 \times 10^{-2}$ \\
\hline
\end{tabular}

Although the relative spectral composition of light at that depth was not directly measured, the greater depth will likely result in increased relative abundance of mid-spectral wavelengths, to which the larvae are photoresponsive, with relatively less abundance of blue and red wavelengths. This relative decrease in blue and red wavelengths with depth results from greater extinction of red light by seawater, blue light by dissolved matter and both red and blue light by phytoplankton (Kishino 1981). In a related field study, nearly $100 \%$ of the red drum larvae (2.0 to $6.0 \mathrm{~mm} \mathrm{SL}$ ) collected in Lydia Ann Channel at a depth of approximately $5 \mathrm{~m}$ had prey in their guts throughout the daylight hours, with much lower percentages at night, further evidence of visual predation at depth (G.J.H. unpubl.).

Considering light intensity alone, we conclude that there is no spatial refuge from visual predation by 
these larvae in these shallow systems. Daytime clumping on or near the bottom by potential prey may minimize visual predation by locating prey in darker regions, but there is sufficient light there for visual predation to occur. While Beaufort and Lydia Ann Channels appear to be shallow enough to allow visual predation throughout the water column during daylight hours, deeper estuaries or channels may optically restrict the depth range and/or portion of the daylight photoperiod for visual predation by red drum larvae.

Acknowledgements. Robin Brinkmeyer, Meredith Morrill and Lara Whitledge (University of Texas Marine Science Institute) assisted in daily sorting of red drum larvae into experimental groups. Kenneth Dunton (University of Texas Marine Science Institute) provided field light data from Lydia Ann Channel. Larry Cahoon (University of North Carolina, Wilmington) assisted in collecting near-bottom field light data from Beaufort Channel. Susan Kilham (Drexel University) provided the scanning spectroradiometer used for spectral light measurements in Beaufort Channel. Joseph Ramus (Duke University Marine Laboratory) loaned us his LI-COR 193S spherical quantum sensor and LI-COR printing integrator (Model 550) used to convert the October, near-bottom downwelling light measurements in Beaufort Channel to $4 \pi$ quantal units and to directly measure light levels there in December and June-July. Thomas Cronin (University of Maryland, Baltimore County) provided spectral scans of the experimental lamps. Susan Kaiser (Rutgers University Marine Field Station), Jack Lynch (University of Pennsylvania) and Laura Lynch (Rutgers University) assisted with preparation of the figures. We thank these people for their assistance. We also thank 3 anonymous reviewers for improving the manuscript through their constructive comments. This research was sponsored in part by the Rutgers University Institute of $\mathrm{Ma}$ rine and Coastal Sciences, Grant No. 2-01165 to D.S. and the Sid W. Richardson Foundation, Grant No. 90-70 to G.J.H., as well as personal funding. This is contribution no. 93-36 of the Institute of Marine and Coastal Sciences, Rutgers University.

\section{LITERATURE CITED}

Blaxter, J. H. S. (1968a). Visual thresholds and spectral sensitivity of herring larvae. J. exp. Biol. 48: 39-53

Blaxter, J. H. S. (1968b). Light intensity, vision, and feeding in young plaice. J. exp. mar. Biol. Ecol. 2: 293-307

Blaxter, J. H. S. (1969). Visual thresholds and spectral sensitivity of flatfish larvae. J. exp. Biol. 51: 221-230

Blaxter, J. H. S. (1975). The eyes of larval fish. In: Ali, M. A. (ed.) Vision in fishes. New approaches in research. Plenum Press, New York, p. 427-443

Blaxter, J. H. S. (1986). Development of sense organs and behaviour of teleost larvae with special reference to feeding and predator avoidance. Trans. Am. Fish. Soc. 115: $98-114$

Blaxter, J. H. S., Staines, M. (1970). Pure-cone retinae and retinomotor responses in larval teleosts. J. mar. biol. Ass. U.K. $50: 449-460$

Branchek, T (1984). The development of photoreceptors in the zebrafish, Brachydanio rerio. II. Function. J. comp. Neurol. 224: 116-122
Champalbert, G., Macquart-Moulin, C., Patriti, G., Chiki, D. (1991). Ontogenic variations in the phototaxis of larval and juvenile sole Solea solea L. J. exp. mar. Biol. Ecol. 149: $207-225$

Durbin, A. G. (1979). Food selection by plankton feeding fishes. In: Clepper, M. (ed.) International symposium on predator-prey systems in fish communities and their role in fisheries management, Atlanta, Georgia, July 24-27, 1978. Sport Fishing Institute, Washington, DC, p. $203-218$

Evans, B. I., Fernald, R. D. (1990). Metamorphosis and fish vision. J. Neurobiol. 21: 1037-1052

Forward, R. B. Jr (1974). Negative phototaxis in crustacean larvae: possible functional significance. J. exp. mar. Biol. Ecol. 16: 11-17

Forward, R. B. Jr (1976). A shadow response in a larval crustacean. Biol. Bull. 115: 126-140

Forward, R. B. Jr (1977). Occurrence of a shadow response among brachyuran larvae. Mar. Biol. 39: 331-341

Forward, R. B. Jr (1986). A reconsideration of the shadow response of a larval crustacean. Mar. Behav. Physiol. 12: 99-113

Forward, R. B. Jr (1988). Diel vertical migration: zooplankton photobiology and behaviour. Oceanogr. mar. Biol. A. Rev. 26: $361-393$

Forward, R. B. Jr, Costlow, J. D. Jr (1974). The ontogeny of phototaxis by larvae of the crab Rhithropanopeus harrisii. Mar. Biol. 26: 27-33

Hairston, N. G. Jr, Li, K. T., Easter, S. S. (1982). Fish vision and the detection of planktonic prey. Science 218: 1240-1242

Herrnkind, W. F. (1968). The breeding of Uca pugilator (Bosc) and mass rearing of the larvae with comments on the behavior of the larval and early crab stages (Brachyura, Ocypodidae). Crustaceana (Suppl.) 2: 214-224

Holt, G. J., Arnold, C. R., Riley, C. M. (1990). Intensive culture of larval and post-larval red drum. Texas A\&M Sea Grant College Program No. TAMU-SG-90-603:53-56

Holt, G. J., Johnson, A. G., Arnold, C. R., Fable, W. A. Jr, Williams, T. D. (1981). Description of eggs and larvae of laboratory reared red drum, Sciaenops ocellata. Copeia 1981: 751-756

Kawamoto, N. Y., Konishi, J. (1955). Diurnal rhythm in phototaxis of fish. Rep. Fac. Fish. prefect. Univ. Mie 2: 7-17

Kishino, M. (1981). Energy balance of underwater radiation related to marine photosynthesis. In: Shibata, K. Iwamura, A., Ikegami, A. (eds.) Biological and chemical utilization of solar energy. Japan Scientific Societies Press, Tokyo, p. $59-69$

Kotrschal, K., Adam, H., Brandstatter, R., Junger, H., Zaunreiter, M., Goldschmid, A. (1990). Larval size constraints determine directional ontogenetic shifts in the visual system of teleosts. A mini-review. Z. zool. Syst. Evol.Forsch. 28: $166-182$

Lee, W. Y., Holt, G. J., Annold, C. R. (1984). Growth of red drum larvae in the laboratory. Trans. Am. Fish. Soc. 113: $243-246$

Li, K. T., Wetterer, J. K., Hairston, N. G. Jr (1985). Fish size, visual resolution, and prey selectivity. Ecology 66: $1729-1735$

Massicotte, B., Dodson, J. J. (1991). Endogenous rhythms in torncod (Microgadus tomcod) post-yolk-sac larvae. Can. J. Zool. 69: 1010-1016

Neave, D. A. (1984). The development of visual acuity in larval plaice (Pleuronectes platessa L.) and turbot (Scophthalmus maximus L.). J. exp. mar Biol. Ecol. 78: 167-175

Nicol, J. A. C. (1963). Some aspects of photoreception and vision in fishes. Adv, mar. Biol. 1: 171-208 
Peters, K. M., McMichael, R. H. Jr (1987). Early life history of the red drum, Sciaenops ocellatus (Pisces: Sciaenidae), in Tampa Bay, Florida. Estuaries 10: 92-107

Roberts, D. E. Jr, Morey, L. A. III, Henderson, G. E., Halscott, K. R. (1978). The effects of delayed feeding, stocking density, and food density on survival, growth, and production of larval red drum (Sciaenops ocellatus). In: Proceedings of the 9 th Annual Meeting of the World Mariculture Society, Atlanta, Georgia, p. 333-343

Sokal, R. R., Rohlf, F. J. (1981). Biometry, 2nd edn. W. H. Freeman \& Co., New York

Stearns, D. E. (1983). Control of nocturnal vertical migration in the calanoid copepod Acartia tonsa Dana in the Newport River estuary, North Carolina. Ph.D. thesis, Department of Zoology, Duke University, Durham

Verheijen, F. J. (1958). The mechanisms of the trapping effect of artificial light sources upon animals. Arch. neer. Zool. 13: $1-107$

Volkova, L. A. (1973). The effect of light intensity on the availability of food organisms to some fishes of Lake Baikal.

This article was submitted to the editor
J. Ichthyol. 13: 591-602

Wales, W. (1975). Extraretinal photosensitivity in fish larvae In: Ali, M. A. (ed.) Vision in fishes. New approaches in research. Plenum Press, New York, p. 445-450

Wales, W. (1984). Photic behaviour and vertical migration in herring larvae. Mar. Behav. Physiol. 11: 139-156

Wanzenböck, J., Schiemer, F. (1989). Prey detection in cyprinids during early development. Can. J. Fish. Aquat. Sci. 46: 995-1001

Wilson, J. E., Forward, R. B. Jr, Costlow, J. D. Jr (1985). Effects of embryonic exposure to sublethal concentrations of Dimilin on the photobehavior of grass shrimp larvae. In: Vernberg, F. J., Thurberg, F. P., Calabrese, A., Vernberg, W. (eds.) Marine pollution and physiology: recent advances. University of South Carolina Press, Columbia, p. $377-396$

Zaunreiter, M., Junger, H., Kotrschal, K. (1991). Retinal morphology of cyprinid fishes: a quantitative histological study of ontogenetic changes and interspecific variation. Vis. Res. 31: 383-394

Manuscript first received: September 14, 1992

Revised version accepted: November 2, 1993 